\title{
ENSINO REMOTO: DESAFIOS A ULTRAPASSAR EM TEMPOS DE PANDEMIA ${ }^{1}$
}

\author{
REMOTE TEACHING: CHALLENGES TO BE \\ EXCEEDED IN PANDEMIC TIMES
}

\section{Fabiane Silva da Fonseca Bronzoni², Marcele Pereira da Rosa Zucolotto ${ }^{3}$, Valeria Iensen Botoluzzi ${ }^{4}$ e Taís Steffenello Ghisleni ${ }^{5}$}

\section{RESUMO}

O presente artigo é fruto da proposta da disciplina de Linguagens e tecnologias aplicadas ao ensino, que integra o curso de Mestrado no Ensino de Humanidades e Linguagens da Universidade Franciscana - UFN, localizada na cidade de Santa Maria, RS. O objetivo deste estudo se configurou em tentar identificar os principais desafios que a pandemia apresentou ao contexto educacional, ao demandar o ensino remoto e mediado pelas tecnologias. Para responder a este questionamento, realizou-se um estudo sobre as chamadas das principais matérias nos sites Por vir e Educação sobre o ensino remoto neste período de pandemia. Para a análise destes dados, buscou-se embasamento teórico a partir das teorias que fomentaram as discussões realizadas no decorrer da disciplina de Linguagens e tecnologias aplicadas ao ensino. Ao final da pesquisa foi possível perceber que os desafios do atual período percorrem em manusear/dominar as tecnologias, manter a saúde mental dos professores e o contato socioafetivo com as crianças/famílias, entre outros que são muito particulares de cada profissional.

Palavras-chave: Ensino, Tecnologias, Reportagens.

\section{ABSTRACT}

This article is the result of the proposal of the discipline of Languages and technologies applied to teaching, which integrates the Master's course in the Teaching of Humanities and Languages at the Franciscan University - UFN, located in the city of Santa Maria, RS. The objective of this study was to try to identify the main challenges that the pandemic presented to the educational context, by demanding remote and technology-mediated teaching. In order to answer this question, a study was carried out on the headlines of the main subjects on the sites 'Por vir' and 'Education' on remote education in this pandemic period. For the analysis of these data, a theoretical basis was sought from the theories that fostered the discussions held during the discipline of Languages and technologies applied to teaching. At the end of the research, it was possible to perceive that the challenges of the current period involve handling / mastering technologies, maintaining the teachers' mental health and socio-affective contact with children / families, among others that are very particular to each professional.

Keywords: Teaching, Technologies, Reports.

\footnotetext{
${ }^{1}$ Artigo produzido na disciplina de Linguagens e Tecnologias Aplicadas ao Ensino, no Mestrado em Ensino de Humanidades e Linguagens da UFN.

${ }^{2}$ Aluna no Mestrado em Ensino de Humanidades e Linguagens da Universidade Franciscana. fabianefonseca@outlook.com

${ }^{3}$ Professora no Mestrado em Ensino de Humanidades e Linguagens da Universidade Franciscana. marcelepr@hotmail.com

${ }^{4}$ Professora no Mestrado em Ensino de Humanidades e Linguagens da Universidade Franciscana. valeria.bortoluzzi@ gmail.com

${ }^{5}$ Professora no Mestrado em Ensino de Humanidades e Linguagens da Universidade Franciscana. taisghisleni@yahoo.com.br
} 


\section{INTRODUÇÃO}

Sabe-se da grande necessidade de inserir as tecnologias em sala de aula, munindo-se das mesmas para oferecer os subsídios necessários para oportunizar novas aprendizagens. Porém, também é fato que não é difícil de encontrar nas instituições de ensino professores que manejam satisfatoriamente as tecnologias, enquanto outros não gostam nem mesmo de tocar no assunto por não se sentirem confortáveis com tais ferramentas.

Também é necessário considerar que alguns profissionais não possuem acesso às tecnologias e, em função disso, possuem pouco ou nenhum trato com as mesmas. Por vezes, até mesmo acabam por incorporar práticas tradicionais, sem dar espaço às novas oportunidades por receio ou por simplesmente não querer desacomodar-se.

Contudo, no decorrer de 2020, todos foram surpreendidos pela pandemia mundial ocasionada em função do novo Coronavírus, que, de acordo com o site Estado de Minas Educação (2020): "Pelo potencial aumentado de contágio da doença em locais com aglomerações, as escolas foram as primeiras a fechar as portas. [...] O ensino remoto virou única opção; a educação em casa, realidade, e sem qualquer experiência prévia". Sendo apresentado desta forma um novo cenário para as instituições de ensino, em que os professores não tiveram outra alternativa senão incluírem-se na sociedade tecnológica.

Assim, surge então a problemática: quais foram os principais desafios que a pandemia apresentou/mobilizou ao contexto educacional, ao demandar o ensino remoto e mediado pelas tecnologias? Para responder a este questionamento, realizou-se um estudo sobre as chamadas das principais matérias nos sites Por vir e Educação sobre o ensino remoto neste período de pandemia, sendo que tais sites foram escolhidos em função de serem sites confiáveis e de grande repercussão no meio educacional.

Para a análise dos dados encontrados, buscou-se embasamento teórico a partir das teorias que fomentaram as discussões realizadas no decorrer da disciplina de Linguagens e tecnologias aplicadas ao ensino, que integra o curso de Mestrado no Ensino de Humanidades e Linguagens da Universidade Franciscana - UFN, e que contou com o estudo de autores como: Thompson (1998), Anastasiou (2015), Szymanski e Meier (2014), Coscarelli e Ribeiro (2014) e Adams e Souza (2016).

Ao final da pesquisa foi possível perceber que os desafios do atual período estão sendo muitos, mas que, em geral, percorrem em manusear/dominar as tecnologias, manter a saúde mental dos professores e o contato socioafetivo com as crianças/famílias, entre outros que são muito particulares de cada profissional.

\section{CONSIDERAÇÕES SOBRE O ENSINO E AS TECNOLOGIAS NA ATUALIDADE}

Sabe-se que o ensino tem sido foco de discussões acerca de reformulações necessárias, o que tem suscitado vários tipos de abordagens, desde as mais tradicionais às emergentes. No entanto, neste tópico, cabem algumas considerações importantes sobre o ensino na atualidade. 
Nesta direção, cabe destacar que um fator importante no processo de ensino é o envolvimento entre professor e estudante. Anastasiou (2015, p. 36) afirma que: "sugere-se, com isso, uma relação contratual, que se efetiva nos programas de aprendizagem, quando professor e estudante têm responsabilidades na conquista do conhecimento, adotando processos de parceria e colaboração". Ou seja, a relação entre professor e estudante torna-se fundamental para uma aprendizagem consolidada.

Assim, atualmente, nota-se maior interesse de estudos científicos acerca do ensino, pensando novas concepções para que o processo de aprendizagem aconteça de forma significativa. Para Santos (2008, p. 33): “A aprendizagem somente ocorre se quatro condições básicas forem atendidas: a motivação, o interesse, a habilidade de compartilhar experiências e a habilidade de interagir com os diferentes contextos".

Deste modo, o desafio que se coloca para os educadores é despertar motivos para a aprendizagem, tornar as aulas interessantes, trabalhar com conteúdos relevantes para a vida de modo geral e tornar a sala de aula um ambiente, de fato, estimulante para a aprendizagem. Anastasiou (2015) segue refletindo, nesta direção, sobre a importância de entender um pouco melhor quem são os estudantes com os quais os educadores trabalham, considerando-os pessoas com sonhos, aspirações e desesperanças, pois somente compreendendo isto, as atividades poderão ser planejadas de modo a que os estudantes sintam-se parte do processo e convocados a fazer as aulas juntamente com o professor.

Considera-se, assim, que as condições para que uma aprendizagem significativa se efetive, desafiam o educador a adotar uma postura de mediador entre o estudante e o conhecimento. Deste modo, essa postura deve levar em conta que o estudante é o sujeito do conhecimento e não um mero receptor de informações. Por isso, é fundamental que o educador se esforce no sentido de envolver os estudantes com os conteúdos e, assim, com a construção de suas próprias aprendizagens.

Vale salientar que o professor possui papel fundamental no processo de ensino ao refletir como deve organizar o processo que seus estudantes irão passar no decorrer da construção do conhecimento. Desta forma, Szymanski e Meier (2014, p. 12) ressaltam que: "É na sistematização da vivência cotidiana reflexiva e crítica que se revela no planejamento de aulas e se materializa no dia a dia da sala de aula que a práxis se consubstancia e se revê apoiada pelos fundamentos teóricos da ação docente, objetivando uma educação de qualidade e intencional".

Deste modo, entende-se que a forma como o professor atua em sala de aula é determinante para o desenvolvimento da aprendizagem dos estudantes. Além disso, no decorrer de 2020, a pandemia mundial surpreendeu a todos, inclusive educandos e educadores, apresentando um novo cenário educacional, em que os professores não tiveram outra alternativa senão incluírem-se na sociedade tecnológica. Assim, tornou-se urgente, para a comunidade educacional, dominar os meios que a contemporaneidade nos apresenta, como as novas tecnologias.

Além da necessidade urgente de se adequar e se ambientar com as novas tecnologias para manter a qualidade do ensino, Thompson (1998) lembra que atualmente a velocidade que temos de 
acesso às informações é indiscutivelmente rápida, dando-se em uma rápida dinâmica de forma global. Nesse sentido, a escola é um dos ambientes de maior necessidade de inclusão neste quesito tecnológico de modo geral e, principalmente, de poder incluir os estudantes neste aspecto, preparando-os para viver a realidade atual marcada pela extrema velocidade de informações. De acordo com Adams e Souza (2016, p. 2): “a escola é uma abertura, uma porta de entrada, a mais privilegiada, para poder viver em sociedade como sujeito capaz de ser o que é na relação com as diferenças ao habitar com outros no mundo".

Ou seja, as relações são intensificadas no ambiente escolar, cabendo aos professores buscar ferramentas necessárias para potencializar essas relações, com auxílio das diferenças de saberes, das bagagens de vivências e de momentos de construção de saberes entre os pares. Neste aspecto, Coscarelli e Ribeiro (2014, p. 6), trazem que:

Formar cidadãos preparados para o mundo contemporâneo é um grande desafio para quem dimensiona e promove a educação. Em plena Era do Conhecimento, na qual inclusão digital e Sociedade da Informação são termos cada vez mais frequentes, o ensino não poderia se esquivar dos avanços tecnológicos que se impõem ao nosso cotidiano.

Nesse sentido, um grande aliado para estes momentos de trocas e até mesmo de busca por conhecimentos são as novas tecnologias e os avanços tecnológicos. Assim, a escola necessita buscar se preparar para que possa proporcionar tal inclusão dos estudantes no mundo tecnológico, sabendo que muitas vezes nem mesmo os professores são incluídos digitalmente. Assim entende-se que a escola também enquanto gestão necessita proporcionar momentos de formação neste aspecto.

Refletindo acerca do que os autores supracitados trazem, vale salientar que as instituições precisaram de uma hora para outra transformarem-se em organizações incluídas tecnologicamente, a partir do cenário atual em tempo de pandemia. Ou seja, as escolas não tiveram tempo para se adequar, buscar conhecimento ou até mesmo treinamento, simplesmente fizeram e estão fazendo o que está dentro de suas possibilidades, tendo em vista tais necessidades, os próprios professores foram em busca de informações para terem sucesso em acompanhar tais mudanças.

Apesar das dificuldades e urgências do momento, percebe-se que, no cenário atual, as tecnologias podem fazer grande diferença na prática pedagógica, atuando como ferramentas potentes para o ensino quando utilizadas de maneira eficaz.

\section{ASPECTOS METODOLÓGICOS}

Para atingir os objetivos deste estudo, foi realizada uma pesquisa quali-quantitativa de cunho bibliográfico, exploratória e descritiva a respeito da temática tratada, partindo primeiramente de pesquisas em bases de dados eletrônicos e livros. Posteriormente, buscou-se nos sites das revistas Educação e Porvir, manchetes publicadas em uma sessão específica da revista publicadas de março a julho, 
com o intuito de observar as temáticas que foram tratadas no período inicial do ensino remoto (março) decorrentes da pandemia.

Vale salientar que os sites foram escolhidos em função de serem confiáveis e de grande repercussão no meio educacional e que as manchetes foram escolhidas da seção "formação docente" de ambos os sites, observando nesse sentido a quantidade de matérias postadas por mês e títulos das mesmas. Nesse sentido observamos tais dados no Quadro 1.

Quadro 01 - Principais manchetes em período pandêmico

\begin{tabular}{|c|c|c|c|c|c|}
\hline Revista: & MARÇO & ABRIL & MAIO & JUNHO & JULHO \\
\hline PORVIR & $\begin{array}{l}\text { "Como aproximar } \\
\text { as famílias da } \\
\text { Escola" }\end{array}$ & - & $\begin{array}{l}\text { "É um erro oferecer so- } \\
\text { luções sem ouvir quem } \\
\text { está do outro lado, diz } \\
\text { professora Gina Vieira" }\end{array}$ & $\begin{array}{l}\text { “A revolução } \\
\text { necessária na } \\
\text { formação dos } \\
\text { professores" }\end{array}$ & $\begin{array}{l}\text { "Professor precisa } \\
\text { ser ouvido antes } \\
\text { de acolher alunos } \\
\text { na volta às aulas" }\end{array}$ \\
\hline Publicações/mês: & 5 & 0 & 4 & 2 & 4 \\
\hline EDUCAÇÃO & $\begin{array}{l}\text { "Kroton oferece } \\
\text { trilha de apren- } \\
\text { dizagem online } \\
\text { e gratuita sobre } \\
\text { BNCC" }\end{array}$ & $\begin{array}{l}\text { "Coronavírus: } \\
\text { Como estão nos- } \\
\text { sos professores" }\end{array}$ & $\begin{array}{l}\text { "Startups da educação } \\
\text { despertam atenção e } \\
\text { ganham espaço no mo- } \\
\text { mento em que ensino a } \\
\text { distância e ferramentas } \\
\text { digitais se tornam } \\
\text { imperativos;" }\end{array}$ & $\begin{array}{l}\text { "Não é momento } \\
\text { de os pais se } \\
\text { transformarem em } \\
\text { alfabetizadores" }\end{array}$ & - \\
\hline Publicações/mês: & 2 & 2 & 3 & 2 & - \\
\hline
\end{tabular}

Fonte: Dados coletados pelas autoras.

Observando as informações do Quadro 1 é importante notar o teor de tais manchetes, entendendo assim quais foram a maioria das preocupações no decorrer do período pandêmico. A partir da análise será construída uma nuvem de palavras como resultado, entendendo o percurso de interesses no período analisado.

Para a análise dos dados encontrados, buscou-se embasamento teórico a partir das teorias que fomentaram as discussões realizadas no decorrer da disciplina de Linguagens e tecnologias aplicadas ao ensino, e que contou com o estudo de autores como: Thompson (1998), Anastasiou (2015), Szymanski e Meier (2014), Coscarelli e Ribeiro (2014) e Adams e Souza (2016). Os autores, portanto, foram selecionados por fazerem parte do estudo realizado na disciplina.

\section{RESULTADOS E DISCUSSÃO}

Para refletir sobre os dados coletados e apresentados no Quadro 01, torna-se importante apresentar que a Revista Educação teve sua criação no ano de 1997, subsidiada pela editora Segmento, sendo dirigida a profissionais da área da educação de ensino básico, tanto da rede pública quanto privada. A revista trata de temas como: políticas públicas, inovações no setor, literatura, pedagogia e 
cultura. Ao longo dos anos, a revista se consagrou por abordar temas polêmicos e profundos. Já o portal Porvir é uma plataforma responsável por conteúdos a respeito de inovações na área da educação no Brasil, criada em 2012, foi mantida durante sete anos pelo Instituto Inspirare e em 2019 tornou-se uma organização autônoma e sem fins lucrativos.

A partir da análise dos títulos das matérias postadas em ambos os sites provenientes da mesma seção denominada "formação docente", foi possível perceber um pouco da dinâmica acerca do período que vivemos, em que a única forma de ensino e de comunicação com os estudantes tem sido o ensino de forma remota.

Nesta direção, é imprescindível considerar que a escola como instituição de ensino esteja dentro do esperado para a sociedade contemporânea, dominando e incentivando os recursos tecnológicos básicos. Porém no atual cenário pandêmico, as instituições não tiveram outra escolha a não ser integrar-se de forma remota à vida das crianças de diferentes níveis de ensino, do modo que lhes foi possível em meio à emergência da situação.

Fica evidente que a escola não possui mais a possibilidade de não se munir dos recursos tecnológicos, esta opção não está mais em questão, até em função de não termos como voltar no tempo, já que a escola vive e trabalha a partir do contexto atual. Nesse sentido, Adams e Souza (2016, p. 5) reforçam que:

\footnotetext{
As novas tecnologias consolidam-se como experiência de velocidade espaço temporal em que não se permite pensar o sentido do ser dos entes. A cultura que vai se constituindo produz a sensação de que, primeiro, não conseguimos viver toda essa transformação e, segundo que, de forma alguma, podemos parar para pensar essa transformação porque ela acontece de modo rápido e ao mesmo tempo envolvente.
}

Ou seja, para que a educação possua um avanço significativo no âmbito das tecnologias é necessário deixar-se desafiar, utilizando-se desse meio para aprimorar as metodologias e ferramentas de ensino. Além disso, deve-se levar em conta a grande velocidade das mudanças tecnológicas também, visto que, assim que algo novo chega, já estão sendo pensadas outras novidades tecnológicas e aquilo que era novo, torna-se obsoleto rapidamente. Desta forma Coscarelli e Ribeiro (2014, p. 6) ainda colocam que:

\footnotetext{
No contexto atual, o grande desafio das escolas, dos educadores e da sociedade civil é a exclusão digital ou o analfabetismo digital. Se as pessoas que estão à frente desse processo não compreendem o que é necessário e o que não é necessário fazer, podem inibir o desenvolvimento de nossas instituições de ensino ou mergulhá-las no envelhecimento prematuro. Não precisamos ir muito longe para saber o que acontece, basta refletirmos sobre a situação atual de nossas escolas públicas.
}

Assim, pensando também no aspecto da velocidade da informação e da tecnologia, Thompson (1998, p. 38) faz menção a respeito do desenvolvimento dos meios de comunicação, que atualmente 
estão incorporados mais do nunca em nossas rotinas familiares: "a crescente disponibilidade de formas simbólicas foi gradualmente alterando as maneiras nas quais as pessoas iam compreendendo o passado e o mundo além de seus contextos sociais imediatos". Ou seja, questões tradicionais utilizadas através da fala como comunicação, por exemplo, foram sendo difundidas com o passar do tempo através da mídia, tornando-nos cada vez mais dependentes deste formato, o qual possuímos hoje.

Nesse sentido, pensando no contexto atual, por meio da busca das manchetes das duas revistas do âmbito educacional, foi possível perceber que no site Porvir, no mês de março, as preocupações da comunidade educativa eram acerca de como aproximar as famílias da escola em tempos remotos. Já no site Educação, a revista já oportunizou uma matéria como recurso de estudo da BNCC, vale ressaltar que o site Porvir teve em março 5 publicações acerca do tema relacionado à pandemia, enquanto o site Educação teve 2. Ou seja, é possível perceber que o site Porvir preparou-se desde o início com as publicações e acessos na temática ensino remoto.

Somando-se a isso, no mês de abril, o site Porvir não postou nenhuma publicação na seção, já o site Educação postou 2 matérias, uma delas intitulada: “Coronavírus: Como estão nossos professores", sendo possível observar então o início de uma preocupação anunciada: a saúde mental dos professores, que já está tão adoecida em todo este processo.

Torna-se relevante acrescentar que, em tempo de atividades remotas uma das questões primordiais que geram uma aprendizagem significativa conta-se bastante prejudicada, que é a necessidade de manter uma relação e uma afetividade entre educandos e educadores. Vimos anteriormente que a aprendizagem se dá através das relações e, essas são marcadas pelos aspectos afetivos. Nesse sentido, é primordial que as escolas, nesta atualidade pandêmica, busquem maneiras para que os professores consigam se aproximar ainda mais de seus estudantes de forma afetiva, por mais que estejam distantes fisicamente. Isso faz lembrar da declaração de Thompson (1998, p. 77) quando fala acerca das relações:

Durante a maior parte da história humana, a grande maioria das interações sociais foram face a face. Os indivíduos se relacionavam entre si principalmente na aproximação e no intercâmbio de formas simbólicas, ou se ocupavam outros tipos de ação dentro de um ambiente físico compartilhado.

Assim, sabemos que não há interação remota que substitua a interação face a face, porém sabemos o quanto a evolução das tecnologias tem afetado as relações como um todo. E, nesta direção, manter as relações e a afetividade, com o ensino de forma remota, transformou-se em mais um dos desafios do período.

Já no mês de maio, os dois sites publicaram matérias referentes a educação em sua interface com as condições impostas pela pandemia. O site Porvir publicou 4 matérias no mês, sendo que uma de suas matérias com o título: É um erro oferecer soluções sem ouvir quem está do outro lado, diz professora Gina Vieira" dando ideia das relações adoecidas que as escolas estão enfrentando de modo geral, juntamente com as famílias e gestores. Já o site Educação, com 3 publicações no mês de maio, 
traz mais opções de como incluir-se com o auxílio de novas ferramentas, com a matéria intitulada: "Startups da educação despertam atenção e ganham espaço no momento em que ensino a distância e ferramentas digitais se tornam imperativos".

A manchete da revista Educação nos dá a ideia de que não existem outras possibilidades de enfrentamento do momento que exige distanciamento social, senão por meio das ferramentas tecnológicas. Além disso, também traz que vêm surgindo ideias de outros profissionais para auxiliar nas melhorias tecnológicas naquilo que é oferecido para a comunidade escolar. Ou seja, de acordo com Thompson (1998, p. 92):

a crescente importância da ação a distância não é somente ligada ao desenvolvimento dos novos meios de comunicação. Uma inteira série de inovações tecnológicas - da pólvora à fissão nuclear, da eletricidade à informação tecnológica - dilatou o alcance da ação humana no espaço e no tempo, algumas vezes de maneiras imprevistas e imprevisíveis.

Desta forma, ressalta-se que jamais se imaginaria que educadores fossem submetidos a uma condição de terem de trabalhar com conteúdos e vivências de forma remota e, mesmo com todas as opções de ferramentas tecnológicas disponibilizadas no contemporâneo, ainda fossem obrigados a inovar em suas práticas e metodologias.

No mês de junho, observou-se nas manchetes que se iniciou um novo olhar a respeito da figura do professor envolvida na pandemia. No site Porvir, que publicou 2 matérias, trouxe o título: "A revolução necessária na formação dos professores", em que fica claro, como já foi transcorrido no presente estudo, que não há outra possibilidade senão aliar-se às tecnologias e investir na formação docente.

Já o site Educação, também com 2 publicações, traz o título: "Não é momento de os pais se transformarem em alfabetizadores", demonstrando a preocupação da escola quanto ao ensino remoto, pois muitas famílias possuem grande dificuldades em desempenhar tal papel. Esta questão das famílias, de terem se tornado presentes de algum modo nas aulas remotas, visto que as mesmas agora acontecem em casa, tem se apresentado com um grande desafio aos educadores. Afinal, os professore agora tem de lidar com famílias que agora estão presentes nas aulas, mas, ao mesmo tempo, distantes das trocas com os educadores e da escola como um todo.

Já em julho, o último mês de observação, apenas o site Porvir fez publicações, 4 ao todo e uma delas com o título: "Professor precisa ser ouvido antes de acolher alunos na volta às aulas", demonstrando que os professores também necessitam de uma recepção diferenciada no momento de retorno e até mesmo atualmente com necessidades de atendimento para cuidados psicológicos em função de todo o cenário e exaustão emocional. Nesta direção, aponta-se como outro desafio aos educadores, imposto pela educação em tempos de pandemia, as dificuldades em manter uma saúde mental adequada pra trabalhar e enfrentar o momento atual.

A partir dos títulos das matérias, como resultado e analisando as palavras envolvidas, foi criada uma nuvem de palavras, que ficou organizada da seguinte forma: 


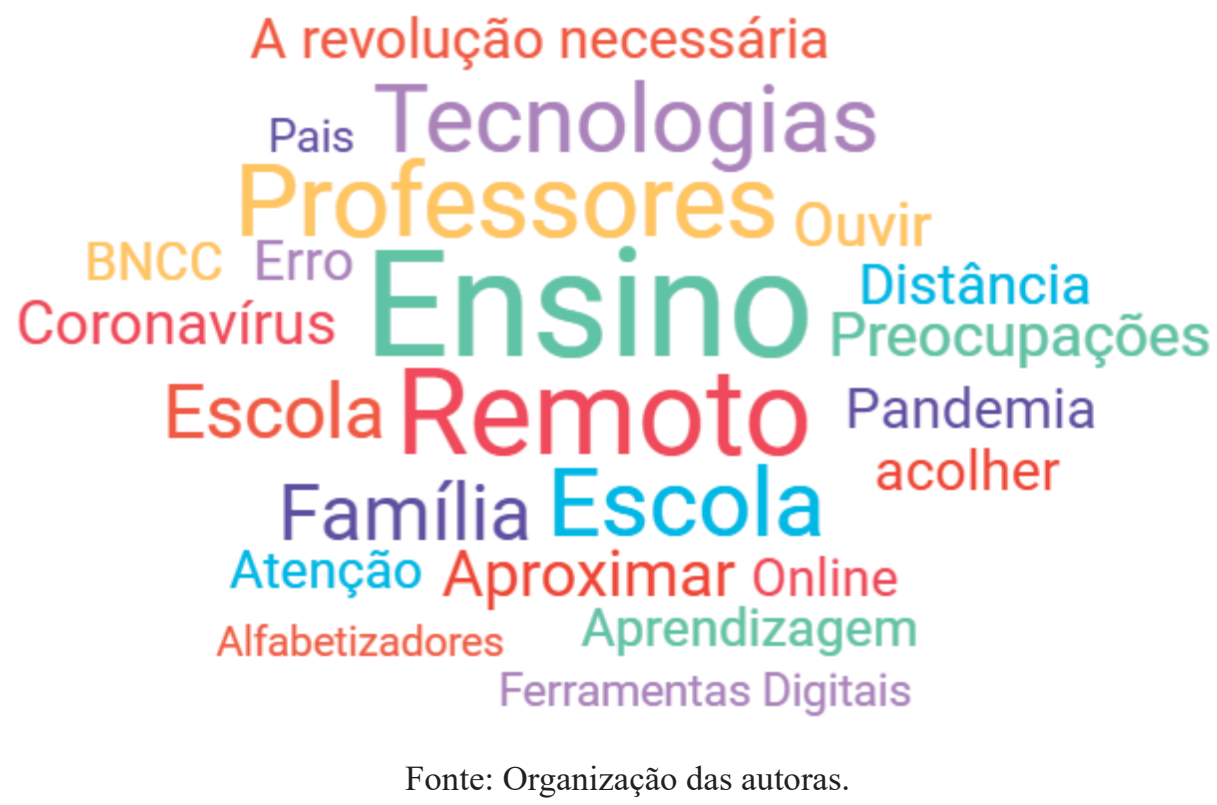

Analisando a nuvem de palavras, fica nítido que o ensino ainda é o ponto chave que liga as instituições escolares às famílias, necessitando da manutenção das relações socioafetivas no atual período, que poderá surtir efeitos positivos quando o diálogo entre os envolvidos nos processos se der de forma mais efetiva ou presencial. Diante disso, Coscarelli e Ribeiro $(2014$, p. 7$)$ expõem que:

[...] instituições de ensino e professores gozarão de grande longevidade se tiverem uma direção segura para saberem o que estão fazendo, para onde estão indo e o que farão quando chegarem lá. Além de muita flexibilidade para romper com métodos e metodologias do passado, inovando suas estratégias por meios das tecnologias disponíveis na Era do Conhecimento.

Ou seja, será no decorrer desta busca pela informação e pela inserção na sociedade da informação que a escola ganhará fôlego, pensando novas possibilidades para a construção do conhecimento, conhecimento crítico e produtivo, não apenas conhecimentos transmitidos de forma unilateral, pelo contrário, conhecimentos que sejam produzidos em conjunto com a bagagem que o estudante traz de seu contexto. Além disso, estar ciente de onde querem chegar é um diferencial no momento atual, em que os professores e instituições foram pegos de surpresa pelo cenário do ensino de forma remota.

\section{CONSIDERAÇÕES FINAIS}

Em suma, entende-se que o período atual decorrente da pandemia de coronavírus é crítico de maneira geral. Período este em que as relações estão afetadas, o setor econômico frágil, em que já atinge a maioria das escolas privadas, sendo estas de porte pequeno ou grande. Nesse sentido, percebe-se a importância do professor nos momentos de aprendizagem e as famílias e estudantes acabaram 
percebendo isso na prática, afinal, muitos pais precisaram se colocar na posição de professor e filhos na posição de alunos dos pais.

Além disso, por meio dos resultados da pesquisa, foi possível perceber que os sites abordaram temáticas muito pertinentes ao período que vivenciamos. Ambos os sites demonstraram inicialmente a preocupação de envolver os professores e relatar suas dificuldades em incluírem-se neste mundo tão tecnológico, que acabou chegando de surpresa para muitos professores.

Não há como negar que as tecnologias estão tendo um papel fundamental no processo educacional como um todo. Assim, este estudo salienta a relevância de o professor estar inserido na era do conhecimento e nas tecnologias para manter a qualidade de seu ensino, mas que esta inserção acaba sendo percebida para muitos educadores como um grande desafio.

Este estudo também apontou para os desafios aos educadores relacionados com a necessidade e importância de que as relações e a afetividade poder ser mantida. Afinal, o distanciamento social exigido pelo momento pandêmico afastou ainda mais educadores e famílias. Percebeu-se que a relação das famílias com a escola ficou bastante fragilizada no período de pandemia, sem contar nas questões emocionais que acabaram por acometer os professores.

Assim, percebemos que os desafios do atual período percorrem em manusear/dominar as tecnologias, saúde mental dos professores, contato socioafetivo com as crianças/famílias, entre outros que são muito particulares de cada profissional. Obviamente que a educação de forma geral, não será mais a mesma quando este período chegar ao fim, nem mesmo os professores e seu olhar diante de situações de aprendizagem no cotidiano escolar.

\section{REFERÊNCIAS}

ADAMS, A.; SOUZA, A. E. Linguagem e educação: reflexões acerca das novas tecnologias da comunicação. Linguagem em (Dis)curso, v. 16, n. 1, p. 169-179, 2016.

ANASTASIOU, L. G. C. Ensinar, aprender, apreender e processos de ensinagem. In: ANASTASIOU, L. G. C.; ALVES, L. P. (Orgs.) Processos de ensinagem na universidade: pressupostos para as estratégias de trabalho em aula. 10. ed. Joinvile: Editora Univille, 2015.

COSCARELLI, C. V.; RIBEIRO, A. E. (Orgs.). Letramento digital: aspectos sociais e possibilidades pedagógicas. Belo Horizonte: Autêntica Editora, 2014.

CASAGRANDE, R. A revolução necessária na formação dos professores. Porvir. Junho/2020. Disponível em: https://bit.ly/35aI66A. Acesso em: 18. Jun. 2020. 
EDUCAÇÃO, Revista. Kronton oferece trilha de aprendizagem online e gratuita sobre BNCC. Março/2020. Disponível em: https://bit.ly/2Ia4PqN. Acesso em: 18. Jun. 2020.

EDUCAÇÃO, Revista. Coronavírus: Como estão nossos professores. Abril/2020. Disponível em: https://bit.ly/32su8v2. Acesso em: 18. Jun. 2020.

EDUCAÇÃO, Revista. Não é momento de os pais se tornarem alfabetizadores. Junho/2020. Disponível em: https://bit.ly/2IiOaBi. Acesso em: 18. Jun.2020

EDUCAÇÃO, Revista. Startups da educação despertam atenção e ganham espaço no momento em que ensino a distância e ferramentas digitais se tornam imperativos. Maio/2020. Disponível em: https://bit.ly/3eEutzL. Acesso em: 18. Jun.2020

LOPES, M. Como aproximar as famílias da escola? Revista Porvir. Março/2020 Disponível em: https://bit.ly/32qdUT4. Acesso em: 18. Jun. 2020.

PORVIR, Revista. É um erro oferecer soluções sem ouvir quem está do outro lado, diz professora Gina Vieira. Maio/2020. Disponível em: https://bit.ly/3n3OLFN. Acesso em: 18. Jun. 2020.

SANTOS, J. C. F. Aprendizagem Significativa: modalidades de aprendizagem e o papel do professor. Porto Alegre: Mediação, 2008.

SZYMANSKI, M. L.; MÉIER, B. M. W. Concepções de ensino e de aprendizagem: superando a burocracia curricular. Revista de Administração Educacional. v. 1, n. 2, p. 62-74, 2014.

THOMPSON, J. B. A mídia e a modernidade: uma teoria social da mídia. Petrópolis: Vozes, 1998.

VARELLA, T. Professor precisa ser ouvido antes de acolher alunos na volta às aulas. Julho/2020. Disponível em: https://bit.ly/2JGovCP. Acesso em: 18. Jun. 2020. 
